\title{
Review of: "Emergence of blaNDM-1 and blaVIM producing Gram-negative bacilli in ventilator- associated pneumonia at AMR Surveillance Regional Reference Laboratory in India"
}

\author{
ESWARAPPA PRADEEP BULAGONDA ${ }^{1}$ \\ 1 Sri Sathya Sai Institute of Higher Learning
}

Potential competing interests: The author(s) declared that no potential competing interests exist.

Dear Sir/Madam,

Mithlesh Kumari et al. described the emergence of bla $a_{\mathrm{NDM}-1}$ and blavIM among ventilator associated pneumonia causing gram negative bacterial pathogens. It's an excellent study; the tables, figures, methods, and results are very well presented. It is most relevant in the current context because many patients are being subjected to ventilator support due to Covid-19 and are at high risk of developing VAPs.

I observed a minor limitation in the study with regard to PCR screening for carbapenem resistance genes. The isolates were screened only for three carbapenemase genes despite $>58 \%$ of them being resistant to carbapenems. Screening for other MBL genes like bla $\mathrm{OXA}_{\mathrm{A}}$ (and its multiple variants), b/a $a_{\mathrm{KPC}}, b / a_{\mathrm{GIM}}, b / a_{\mathrm{SIM}}$, $b_{\text {bPM }}$, etc. may have given a much better insight into their involvement in the emergence of carbapenem resistance associated with VAPs. Also, there are various variants of NDM genes that are now prevalent, but the authors have not mentioned which subtype was screened in the study or if it was a consensus sequence from all the variants. 